\title{
Evaluation of microleakage of three different endodontic sealers in the presence and absence of moisture
}

\author{
Hamid Razavian $^{\circledR}$, Kimia Hanjani ${ }^{\circledR}$, Kiana Hanjani ${ }^{*}{ }^{\circledR}$, Hesam Mirmohammadi ${ }^{\circledR}$, Alireza Shabanian Boroujeni ${ }^{(\mathbb{}}$ \\ ${ }^{1}$ Department of Endodontics, Dental Materials Research Center, Dental Research Institute, School of Dentistry, Isfahan \\ University of Medical Sciences, Isfahan, Iran \\ ${ }^{2}$ Dental Student, School of Dentistry, Isfahan University of Medical Sciences, Isfahan, Iran \\ ${ }^{3}$ Post Graduate Student, Department of Pediatric Dentistry, School of Dentistry, Shahid Beheshti University of Medical Science, \\ Tehran, Iran \\ ${ }^{4}$ Department of Endodontology and Preventive Dentistry, Academic Center for Dentistry Amsterdam, Amsterdam, the \\ Netherlands
}

*Corresponding Author: Kimia Hanjani, Dentistry Student; 3rd floor, 25th Building, Bagh Zereshk Alley, Chaharbagh-Bala Street, Isfahan, Iran. Tel: +989134096938, Email: Hanjanikimia@gmail.com

\begin{abstract}
Background and aims: AH26, Master-Dent, and Endoseal mineral trioxide aggregate (MTA) are three different types of sealers. The purpose of this study was to assess and compare THE apical seal of the root canal-treated teeth with the above-mentioned sealers in the presence and absence of moisture using the fluid filtration method.

Methods: To this end, 54 freshly extracted single root canal human canines were selected for this study. The canals were prepared using rotary instruments, and then sodium hypochlorite was applied as an irrigation solution in this protocol. The specimens were randomly divided into three groups of 18 . One group was obturated with the gutta-percha by the cold lateral compaction technique. Half of one of the aforementioned sealers belonged to the group of moistened teeth and the other half to the group of the dried teeth. Microleakage in all groups was assessed 3 months after the obturation of canals by the fluid filtration method. The data were analyzed using ANOVA and Tukey's post hoc tests, and the level of significance was set at $P<0.05$.

Results: The results showed that the minimum and maximum micro-leakage belonged to Masterdent dry (mean leakage $=1.7778 \mu \mathrm{L}$ $\mathrm{min} / \mathrm{Cm}_{\mathrm{H} 20}$ ) and Endoseal-MTA dry (mean leakage $=3.5000 \mu \mathrm{L} / \mathrm{min} / \mathrm{Cm}_{\mathrm{H} 20}$ ), respectively. All three groups of sealers exhibited a significant difference in apical micro-leakage between dry and moist conditions ( $P_{\text {Masterdent }}<0.001, \mathrm{P}_{\mathrm{AH} 26}=0.002$, and $\left.P_{\text {EndoseaL-MTA }}=0.007\right)$.

Conclusion: The findings of this experimental study demonstrated that Masterdent provided the least apical micro-leakage under dry conditions while Endoseal-MTA had the highest micro-leakage under these conditions. There was a significant difference between dry and moist conditions in all groups.

Keywords: Microleakage, Fluid filtration, Root canal obturation, Moisture, Sealer
\end{abstract}

Received: 2 August 2021, Accepted: 28 November 2021, ePublished: 26 January 2022

Introduction

Endodontic obturation includes complete threedimensional filling of the dental root canal with materials that present satisfactory physical and biological properties (1-3). Ideally, the filling material should sufficiently seal the root canal and simultaneously prevent fluid penetration into the root canal space, stimulate the resolution of periapical pathologies, and encourage the deposition of cementum to obtain a biological seal (3).

An inappropriate apical seal has been reported as the most important cause of root treatment failure (4). It was suggested to dry the root canal before obturation since it increases the adherence of the filling material to the dentin walls of the canal before the appearance of mineral trioxide aggregate (MTA)-based sealers $(5,6)$.

Resin-based endodontic sealers such as AH26 have received considerable attention from endodontists because of their good physical-chemical and biological properties (7). Other sealers, especially those that are based on zinc oxide eugenol (ZOE) or MTA (8), could have better biological properties.

Nowadays, one of the most commonly used sealers in root canal treatment is the ZOE-based sealer, which has been qualified for endodontic purposes. The powder of this sealer contains zinc oxide $(\mathrm{ZnO})$, which is the valuable component of this sealer and blends with a liquid, generally eugenol (9).

Resin-based sealers have good physical features, sealing ability, adequate biologic function, and micromechanical retention to root dentin. Sealers such as AH-26 are routinely employed as control materials in endodontic research because of their low solubility, long-lasting stability, and adequate retention to dentin (10).

Bioceramic-based materials containing calcium silicate and/or calcium phosphate have been considerably noticed due to their physical and biological properties such as their biocompatibility, alkaline $\mathrm{pH}$, chemical stability in the biological environment, and the lack of shrinkage.

(C) 2022 The Author(s); Published by Shahrekord University of Medical Sciences. This is an open-access article distributed under the terms of the Creative Commons Attribution License (http://creativecommons.org/licenses/by/4.0), which permits unrestricted use, distribution, and reproduction in any medium, provided the original work is properly cited. 
For example, a premixed bioceramic endodontic sealer, EndoSequence BC Sealer, and an experimental MTAbased root canal sealer showed optimal physicochemical properties for the root canal sealer (11).

Although MTA is remarkably biocompatible when employed in pulpotomies (12), root perforations (13), and retrograde obturations (14), as well as an account of its difficult handling and insertion, it is not commonly applied as a root canal filling material (15). However, more recently, some manufacturers have added specific elements to MTA-based cements such as ProRoot Endo Sealer, CPM. Sealer, and MTA-Obtura in order to integrate the favorable biological properties of MTA into an easy to handle and to insert material (1).

Various studies have investigated the sealing ability of different sealers (16), and different amounts of the remaining moisture in the root canal have been shown to change the sealing properties of conventional and resin-based sealers (17). Contrarily, some studies have focused on apical micro-leakage using Masterdent and Endoseal MTA sealers in comparison with other routinely used sealers, or the effect of the moisture on the apical microleakage of these sealers (18-20). Many studies have suggested that apical microleakage happens due to delayed bleeding, interstitial fluid, or irrigation solution remnants, particularly sodium hypochlorite $(21,22)$. These all have certainly happened out of the sight of the operator, but recent research has also claimed that residual moisture does not alter the mean value of microleakage (20) Based on these observations, the present study aimed to analyze the apical seal of AH26, Masterdent, and Endoseal MTA in the presence and absence of residual moisture within the canal by the fluid filtration method at the observation period of 90 days.

\section{Materials and Methods}

According to the sample size calculation formula (23), this experimental study included 54 extracted teeth collected within one month from dental clinics in Isfahan, Iran. This research process was performed by two endodontists, two dentistry students, and one pediatric dentistry resident. The inclusion criteria were maxillary or mandibular canine, no restoration or decay lower down the cementoenamel junction (CEJ), complete root formation without the signs of internal or external resorption, straight coneshaped root with curvature less than $30^{\circ}$ in the apical third, no fracture or crack in the root, and no calcification in the root canal. On the other hand, the exclusion criteria included $\mathrm{K}$ files \#10 and \#15 not passing beyond $14 \mathrm{~mm}$ from CEJ into the root canal (22).

$$
\begin{aligned}
& n=\frac{\left(z_{1-\frac{\alpha}{2}}+z_{1-\beta}\right)^{2}\left(\sigma_{1}^{2}+\sigma_{2}^{2}\right)}{d^{2}} \\
& \alpha=0.05 z_{1-\frac{\alpha}{2}}=1.96 \\
& 1-\beta=0.80 Z_{1-\beta}=0.8
\end{aligned}
$$

$\sigma_{1}, \sigma_{2} \simeq 0.0036$

$\mathrm{d}=0.00336$

With 18 samples for dry and wet conditions ( 9 samples in each group), it is 0.80 probable that the difference will be at least equal to $\mathrm{d}=0.00336$ between the average microleakage of sealers at the 0.05 significant level.

\section{Preparation of the teeth}

Initially, the teeth were debrided by eliminating all attached hard and soft tissues and immersing in $1000 \mathrm{~mL}$ of 5.25\% sodium hypochlorite (Golrang Company, Tehran, Iran) for 24 hours. Then, the teeth were stored in the container with a lid containing $0.9 \%$ sterile saline (Iran transfusion product Company, Tehran, Iran) at room temperature until the following processing. Out of 160 extracted teeth in the recent month, 54 human maxillary canine teeth with acceptable appearance meeting the inclusion criteria were selected before starting the study. The sampling method was based on the simple random sampling method. These 54 acceptable samples were numbered, and then 9 teeth were selected for each of the 6 groups using a computerbased random number generator which almost always uses a pseudo-random number generation method (24). Their crowns were cut near the CEJ by a diamond disc (Tizkavan, Tehran, Iran) and a high-speed handpiece (NSK, Tokyo, Japan) with water coolant, which is perpendicular to the long axis, to achieve a $15 \mathrm{~mm}$ root length for all samples measured by a digital caliper (Goanjigo SR 44, China). All prepared teeth were again held in $0.9 \%$ sterile saline at room temperature until the test time. The working length was confirmed using a \#10 K-file (Dentsply Maillefer, Ballaigues, Switzerland) by decreasing $1 \mathrm{~mm}$ from the file length after appearing through the apical foramen. Following apical patency verification using a \#10 K-file, the teeth were instrumented by the Denco rotary instrument (Shenzhen Denco Medical Company, Guangdong, China) and shaped to file \#80, establishing a \#40 master apical cone for all the samples. In this protocol, sodium hypochlorite was used as an irrigation solution. After shaping all the canals, the smear layer was removed by root canal irrigation with hypochlorite for 1 minute and then $17 \%$ EDTA for 1 minute (10) and preferably normal saline in between to prevent any unpredictable interaction. Subsequently, all the canals were flushed with normal saline. All the teeth were evenly prepared by this time. Afterward, the groups were organized to have 18 teeth for each sealer, half of which belonged to the group of moistened teeth and the other half was related to the group of the dried teeth. Masterdent, Endoseal MTA, and AH26 were applied in this study. To prepare the dry group, the canals were dried by paper points with a similar size and length as the master apical file until the thorough elimination of the moisture. In the moistened group, however, the canals were not completely dried after flushing with normal saline, as only the moisture of the 
pulp chamber and the coronal two-thirds of the canal would be displaced using a paper point with a greater size compared to the master apical file. Next, in each group, the sealers were mixed according to manufacturers' instructions and inserted into the root canals coating all the walls by a spreader (MANI, Japan) with the size and length of the master apical cone introduced $0.5 \mathrm{~mm}$ short of the working length and always with the same amount of sealer. Afterward, the gutta-percha point reached the working length; the extruded sealer throughout the foramen was gently removed from the root surface with gauze. The root canals were filled and obturated by (DiaDent, Korea) gutta-percha cones by applying cold lateral condensation. The excess gutta-percha and sealer were removed by alcohol-soaked cotton. After the radiography procedure to ensure proper obturation, the teeth were incubated at $37^{\circ} \mathrm{C}$ and $100 \%$ humidity for setting the sealers $(8,19,10)$.

After 90 days, the roots were connected to 54 plastic tubes (Guihaa, China), and the interface between the teeth and plastic tubes was sealed with two layers of cyanoacrylate glue (Osaka, Japan) at the apical side and then sealed with Parafilm (Parafilm, Laboratory films, Chicago) as well. Before mounting the roots, except for an area of $2.0 \mathrm{~mm}$ around the root apex, the rest of the root surfaces were covered with two layers of nail polish to eliminate the effect of lateral canals (18, 25-27).

Leakage was evaluated by the fluid filtration method using a pressure equivalent to $10 \mathrm{psi}$ as reported by Derkson et al (28) and adjusted for Endodontics by Wu and Wesselink (26). Four measurements were performed for each sample at 2-minute intervals for a total of 8 minutes at 90 days after filling. The amount of leakage was presented as $\mu \mathrm{L} / \mathrm{min}-1.10 \mathrm{psi}$. Finally, the designed device was used for assessing bubble movements, and the data were quantified in $\mu \mathrm{L} / \mathrm{min} / \mathrm{CmH} 2 \mathrm{O}$ and analyzed by oneway ANOVA and Tukey's post-hoc tests.

\section{Results}

The results showed microleakage in all samples over 90 days. Table 1 presents the mean leakage values and standard deviations for different sealers under wet and dry conditions. Further, the leakage of all the sealers was compared two by two, and their $P$ values are mentioned in Table 2.

The lowest amount of micro-leakage was observed in the Masterdent sealer under dry conditions while the highest micro-leakage was related to the Endoseal-MTA sealer under dry conditions. At the 3-month period, ANOVA test results revealed statistically significant differences in the amount of micro-leakage between almost all the studied groups of sealers $(P<0.05)$. The mean microleakage in all sealers was significantly lower on dry canal conditions compared with moist canal conditions except for the Endoseal-MTA sealer (Table 1). In the presence of moisture, the type of the sealer had no meaningful effect on the amount of the micro-leakages of the sealers but in
Table 1. Mean leakage by moisture

\begin{tabular}{lccc}
\hline Condition & AH26 & Masterdent & Endoseal MTA \\
\hline Dry & $2.0625 \pm 0.41726$ & $1.7778 \pm 0.44096$ & $3.5000 \pm 0.5000$ \\
Moist & $3.1875 \pm 0.65124$ & $2.7778 \pm 0.50690$ & $2.4375 \pm 0.56300$ \\
$P$ value & 0.002 & $<0.001$ & 0.007 \\
\hline
\end{tabular}

Note. MTA: mineral trioxide aggregate.

Table 2. Two by two comparisons of the leakage of all sealers in the presence and absence of moisture

\begin{tabular}{lcc}
\hline Group 1 & Group 2 & P value \\
\hline \multirow{2}{*}{ W-AH26 } & D-AH26 & $0.002^{*}$ \\
& W-Masterdent & 0.768 \\
& D-Masterdent & $<0.001^{*}$ \\
W-Endoseal MTA & 0.112 \\
D-Endoseal MTA & 0.916 \\
D-AH26 & W-Masterdent & 0.052 \\
& D-Masterdent & 0.624 \\
W-Masterdent & W-Endoseal MTA & 0.641 \\
& D-Endoseal MTA & $<0.001^{*}$ \\
& D-Masterdent & $<0.001^{*}$ \\
W-Endoseal MTA & W-Endoseal MTA & 0.742 \\
\hline D-Masterdent & D-Endoseal MTA & 0.179 \\
\hline & W-Endoseal MTA & $0.032^{*}$ \\
& D-Endoseal MTA & $<0.001^{*}$ \\
\hline
\end{tabular}

Note. MTA: Mineral trioxide aggregate.

"The mean difference is significant at the 0.05 level.

dry condition, there was a remarkable difference between the Endoseal-MTA and Masterdent groups $(P<0.001)$ and the Endoseal MTA and AH26 groups $(P<0.001)$.

\section{Discussion}

Based on the results of the present study, the lowest amount of micro-leakage belonged to the Masterdent group in dry conditions whereas the highest amount was found in the Endoseal-MTA group in dry conditions. In AH26, Masterdent, and Endoseal-MTA group, there was a statistically notable difference in micro-leakage between dry and wet conditions. MTA Fillapex was previously demonstrated to have a better apical seal compared to AH26 (29). However, in the present study, Endoseal-MTA had the highest rate of micro-leakage in the presence and absence of moisture. This divergence may be explained by the hydrophilic properties of MTA in the Endoseal-MTA group among these three types of sealer.

Sealers containing MTA have hydrophilic characteristics, and some recent studies have concluded that moisture is needed for setting MTA-based sealers. They even claim that if MTA plays the role of a sealer, complete drying of the canal before placing the sealer might even prevent complete setting. It is also accepted that it may be favorable to leave the canals with a bit of moisture before root canal obturation with such sealers (6). The individual difference in handling and employing the sealers can be 
a reason for this difference. Moreover, the results may be affected by the biases of the applied test method in this study. Furthermore, the amount of residual moisture left in the root canals may have been insufficient in our MTAbased group of sealers, or the setting of the sealer may be uncompleted, and the like.

The adhesion quality of some sealers to root canal dentin could be influenced by the amount of moisture left in the root canals before the obturation process. For example, in the study of Ehsani et al, using an insulin syringe needle (Helal Medical Equipment Company, Tehran, Iran), $0.02 \mathrm{~mL}$ saline was poured into the canal for its wetting (4). This amount of moisture may have been more or less than the amount of moisture that has been left in the canals. Considering that the leakage difference between the wet and dry groups in the MTA-based sealer was reported to be significant in our study contrary to Ehsani and colleagues' study, the amount of the residual moisture has probably affected apical leakage. Although the apprehension of moisture may vary considerably among dentists, several manufacturers suggested that the root canals be maintained in a wet status to take advantage of the hydrophilic properties of their sealers without specific clinical instructions to reach the optimal degree of residual moisture (17). Nagas et al (17) concluded that the amount of residual moisture can notably have an effect on the adhesion of sealers to root canal dentin. For the mentioned sealers in their article, including $\mathrm{AH}$ Plus and MTA Fillapex, it may be favorable to leave the canals quite wet before filling (17). Similarly, Roggendorf et al (30) showed that humidity resulted in lower microleakage for Apexit, RoekoSeal, and Tubli-Seal while higher values for AH Plus and Ketac-Endo, stating that the remnant moist may act as a lubricant for previously named sealers allowing a better adhesion to the root canal walls, therefore, thorough drying of the root canal dentin may have unfavorably affected linear dye penetration (30).

On the other hand, some other researchers such as Jang et al (31) and Goldman et al (5) suggested totally dried root canals before the obturation process because they believed it may increase the adherence of the filling material to the dentin walls of the canal.

According to Ehsani et al, experiments under moist and dry conditions represented that the AH26 sealer owned the lowest micro-leakage, and the matter of moisture (blood or 5.25\% hypochlorite) had no remarkable effect on the amount of sealer micro-leakage (4).

To recreate the clinical situation more specifically, it is suggested that similar research be conducted in different circumstances (e.g., in the presence of the remaining serum or blood in the prepared root canals).

Supplementary research concentrating on the outcomes of different percentages of residual moisture in root canals on apical seals may reveal useful findings (4).

\section{Conclusion}

This experimental studyaimed to evaluate the microleakage of three types of endodontic sealers in the presence and absence of moisture in order to find the appropriate sealer for when moisture involuntarily remains inside root canals during root canal treatment. Based on our findings, Masterdent represented the least amount of micro-leakage in dry conditions while the Endoseal-MTA group had the highest micro-leakage again under dry conditions. There was a notable difference between dry and moist conditions in all groups. Eventually, the current study had some limitations including the use of only single-rooted teeth, limitations of the fluid filtration method, sample size, duration of observation, and different individual manipulation techniques. More importantly, this was an in vitro study, which may have affected the results.

\section{Acknowledgements}

The authors would like to thank the Dental Materials Research Center of Isfahan and Mashhad University of Medical Sciences and their staff for the sincere collaboration and assistance in data collection.

Authors' Contribution

$\mathrm{HR}, \mathrm{KH}_{1}$ (Kimia Hanjani), and $\mathrm{KH}_{2}$ (Kiana Hanjani) conducted the experiment. $\mathrm{KH}_{1}$ wrote the manuscript and HR supervised the project. HR conceived the study and was in charge of the overall direction and planning. In addition, $\mathrm{KH}_{1}$ and $\mathrm{KH}_{2}$, as well as $\mathrm{HR}$. and $\mathrm{KH}_{1}$ contributed to the preparation of samples and interpretation of the results, respectively. All authors provided critical feedback and helped shape the research, analysis, and manuscript. $\mathrm{HR}$ and $\mathrm{KH}_{1}$ designed the experiments, derived the models, and analyzed the data. $\mathrm{KH}_{2}$ assisted with measurements and helped in performing the simulations. Further, $\mathrm{KH}_{1}$ wrote the manuscript in consultation with $\mathrm{HM}$ and $\mathrm{AS}$. HR verified the analytical methods. HR encouraged $\mathrm{KH}_{1}$ to investigate and supervise the findings of this work. All authors discussed the results and contributed to the final manuscript. $\mathrm{HM}$ devised the project, the main conceptual ideas, and the proof outline. $\mathrm{KH}_{1}$ and AS worked out almost all the technical details and performed the numerical calculations for the suggested experiment. Similarly, $\mathrm{KH}_{1}$ processed the experimental data, performed the analysis, drafted the manuscript, and designed the figures with the help of other authors. HR aided in interpreting the results and worked on the manuscript. All authors discussed the results and commented on the manuscript. Finally, both AS and $\mathrm{KH}_{2}$ contributed to the final version of the manuscript, and $\mathrm{HM}$ supervised the project.

Conflict of Interests

The authors declared no conflict of interests.

\section{Ethical Approval}

Ethical considerations in this study included obtaining permission from the Ethics Committee of Isfahan University of Medical Sciences (Approval ID: IR.MUI.RESEARCH.REC.1400.148).

\section{Funding/Support}

This study was funded by Isfahan University of Medical Sciences (Grant no. 3400208).

\section{References}

1. de Vasconcelos BC, Bernardes RA, Duarte MA, Bramante CM, de Moraes IG. Apical sealing of root canal fillings performed with five different endodontic sealers: analysis by fluid filtration. J Appl Oral Sci. 2011;19(4):324-8. doi: 10.1590/ s1678-77572011005000005.

2. da Silva PJ, Marceliano-Alves MF, Provenzano JC, Dellazari 
RLA, Gonçalves LS, Alves FRF. Quality of root canal filling using a bioceramic sealer in oval canals: a three-dimensional analysis. Eur J Dent. 2021;15(3):475-80. doi: 10.1055/s-00401722095.

3. Almeida MM, Rodrigues CT, Matos AA, Carvalho KK, Silva EJ, Duarte MA, et al. Analysis of the physicochemical properties, cytotoxicity and volumetric changes of $\mathrm{AH}$ Plus, MTA Fillapex and TotalFill BC Sealer. J Clin Exp Dent. 2020;12(11):e1058-e65. doi: 10.4317/jced.57527.

4. Ehsani M, Dehghani A, Abesi F, Khafri S, Ghadiri Dehkordi S. Evaluation of apical micro-leakage of different endodontic sealers in the presence and absence of moisture. J Dent Res Dent Clin Dent Prospects. 2014;8(3):125-9. doi: 10.5681/ joddd.2014.023.

5. Goldman M, White RR, Moser CR, Tenca JI. A comparison of three methods of cleaning and shaping the root canal in vitro. J Endod. 1988;14(1):7-12. doi: 10.1016/s00992399(88)80235-8.

6. Salem Milani A, Firuzi S, Soroush Barhaghi MH, Shahi S, Abdollahi AA. Evaluation of sealing abilitiy of mineral trioxide aggregate mixed with propylene glycol as a root canal sealer: a in vitro study. Dent Res J (Isfahan). 2019;16(4):216-20.

7. Kakoura F, Pantelidou O. Retreatability of root canals filled with gutta percha and a novel bioceramic sealer: a scanning electron microscopy study. J Conserv Dent. 2018;21(6):632-6. doi: 10.4103/jcd.jcd_228_18.

8. Weller RN, Tay KC, Garrett LV, Mai S, Primus CM, Gutmann JL, et al. Microscopic appearance and apical seal of root canals filled with gutta-percha and ProRoot Endo Sealer after immersion in a phosphate-containing fluid. Int Endod J. 2008;41(11):97786. doi: 10.1111/j.1365-2591.2008.01462.x.

9. Javidi M, Dastmalchi P, Zarei M, Shayani Rad M, Ghorbani A. In vitro cytotoxicity of a new nano root canal sealer on human gingival fibroblasts. Iran Endod J. 2017;12(2):220-5. doi: 10.22037/iej.2017.43.

10. Razmi H, Bolhari B, Karamzadeh Dashti N, Fazlyab M. The effect of canal dryness on bond strength of bioceramic and epoxy-resin sealers after irrigation with sodium hypochlorite or chlorhexidine. Iran Endod J. 2016;11(2):129-33. doi: 10.7508/iej.2016.02.011

11. Colombo M, Poggio C, Dagna A, Meravini MV, Riva P, Trovati $\mathrm{F}$, et al. Biological and physico-chemical properties of new root canal sealers. J Clin Exp Dent. 2018;10(2):e120-e6. doi: 10.4317/jced.54548.

12. Lee $M$, Kang $C M$, Song JS, Shin $Y$, Kim S, Kim SO, et al. Biological efficacy of two mineral trioxide aggregate (MTA)based materials in a canine model of pulpotomy. Dent Mater J. 2017;36(1):41-7. doi: 10.4012/dmj.2016-121.

13. Dastorani M, Shourvarzi B, Nojoumi F, Ajami M. Comparison of bacterial microleakage of Endoseal MTA Sealer and ProRoot MTA in root perforation. J Dent (Shiraz). 2021;22(2):96101. doi: 10.30476/dentjods.2020.86042.1164.

14. Valencia YM, Vertuan GC, Alcalde MP, Vivan RR, Reis Só $M V$, Duarte MAH. Effect of irrigating agitation after root end preparation on the wall cleaning and bond strength of calcium silicate material in retrograde obturation. Eur J Dent. 2021;15(4):707-13. doi: 10.1055/s-0041-1729454.

15. An HJ, Yoon H, Jung HI, Shin DH, Song M. Comparison of obturation quality after MTA orthograde filling with various obturation techniques. J Clin Med. 2021;10(8):1719. doi: 10.3390/jcm10081719.

16. Silva Almeida LH, Moraes RR, Morgental RD, Pappen FG.
Are premixed calcium silicate-based endodontic sealers comparable to conventional materials? a systematic review of in vitro studies. J Endod. 2017;43(4):527-35. doi: 10.1016/j. joen.2016.11.019.

17. Nagas E, Uyanik MO, Eymirli A, Cehreli ZC, Vallittu PK, Lassila $\mathrm{LV}$, et al. Dentin moisture conditions affect the adhesion of root canal sealers. J Endod. 2012;38(2):240-4. doi: 10.1016/j. joen.2011.09.027.

18. Kuhre AN, Kessler JR. Effect of moisture on the apical seal of laterally condensed gutta-percha. J Endod. 1993;19(6):27780. doi: 10.1016/s0099-2399(06)80456-5.

19. Gibby SG, Wong Y, Kulild JC, Williams KB, Yao X, Walker MP. Novel methodology to evaluate the effect of residual moisture on epoxy resin sealer/dentine interface: a pilot study. Int Endod J. 2011;44(3):236-44. doi: 10.1111/j.13652591.2010.01806.x.

20. Khalilak Z, Vatanpour M, Javidi M, Mafi M, Afkhami F, Daneshvar F. The effect of blood on apical microleakage of Epiphany and AH26: an in vitro study. Iran Endod J. 2011;6(2):60-4.

21. Tay FR, Loushine RJ, Monticelli F, Weller RN, Breschi L, Ferrari $M$, et al. Effectiveness of resin-coated gutta-percha cones and a dual-cured, hydrophilic methacrylate resin-based sealer in obturating root canals. J Endod. 2005;31(9):659-64. doi: 10.1097/01.don.0000171942.69081.53.

22. Razavian H, Hanjani K. Effect of moisture on the root treated canals' microleakage using two types of resin based sealers. Ann Dent Spec. 2018;6(3):317-20.

23. Barlett JE, Kotrlik JW, Higgins CC. Organizational research: determining appropriate sample size in survey research. Inf Technol Learn Perform J. 2001;19(1):43-50.

24. Deng LY, Lin DKJ. Random number generation for the new century. Am Stat. 2000;54(2):145-50. doi: 10.1080/00031305.2000.10474528.

25. Zarei M, Javidi M, Ghoddusi J, Naghavi N, Roohani E. An in-vitro evaluation of sealing ability of real seal using fluid filtration. Iran Endod J. 2007;2(1):11-4.

26. Wu MK, Wesselink PR. Endodontic leakage studies reconsidered. Part I. Methodology, application and relevance. Int Endod J. 1993;26(1):37-43. doi: 10.1111/j.13652591.1993.tb00540.x.

27. Jafarzadeh H, Nabavi S, Shakeri M, Bidar M, Zamanpour M. The comparison of apical leakage between two obturation techniques (cold lateral condensation and Obtura II) by using fluid filtration method. Razavi Int J Med. 2018;6(1):42-5. doi: 10.5812/rijm.57759.

28. Derkson GD, Pashley DH, Derkson ME. Microleakage measurement of selected restorative materials: a new in vitro method. J Prosthet Dent. 1986;56(4):435-40. doi: 10.1016/0022-3913(86)90384-7.

29. Moradi S, Naghavi N, Rohani E, Javidi M. Evaluation of microleakage following application of a dentin bonding agent as root canal sealer in the presence or absence of smear layer. J Oral Sci. 2009;51(2):207-13. doi: 10.2334/josnusd.51.207.

30. Roggendorf MJ, Ebert J, Petschelt A, Frankenberger R. Influence of moisture on the apical seal of root canal fillings with five different types of sealer. J Endod. 2007;33(1):31-3. doi: 10.1016/j.joen.2006.07.006.

31. Jang JA, Kim HL, Her MJ, Lee KW, Yu MK. Effect of moisture on sealing ability of root canal filling with different types of sealer through the glucose penetration model. J Korean Acad Conserv Dent. 2010;35(5):335-43. 